\title{
Blood profile of lactating crossbred cows rearing at Bangladesh Agricultural University Dairy Farm
}

\author{
H Rafsanjanny ${ }^{1}$, MAH Sarker ${ }^{1}$, MZ Islam ${ }^{1}$, KMS Islam $^{2}$, MR Haque $^{3}$, MN Islam ${ }^{1}$ and MSR \\ Siddiki $^{1 *}$
}

${ }^{1}$ Department of Dairy Science, Bangladesh Agricultural University, Mymensingh-2202; ${ }^{2}$ Department of Animal Nutrition, Bangladesh Agricultural University, Mymensingh; ${ }^{3}$ Department of Livestock Services (DLS), Farmgate, Dhaka-1215, Bangladesh

\begin{abstract}
This study aimed to analyze the hemato profile of crossbred lactating cows reared at Bangladesh Agricultural University (BAU) Dairy Farm. Thirty-two (32) healthy crossbred lactating cows of HolsteinFrisian (HF), Jersey (J), Sindhi Sahiwal (SS) and Red Chittagong (RCC) were selected for the study and divided into four (04) groups. The cows were allowed to feed and manage according to dairy farm own scheduled-ration. The collected blood samples were analyzed for hematological and biochemical parameters viz. Hemoglobin ( $\mathrm{Hb}$ ), Packed cell volume (PCV), Total leukocyte count (TLC), and Total erythrocyte count (TEC) and Serum urea, Glucose, Albumin, Calcium, and Phosphorus, respectively by using an automated chemistry analyzer. The results revealed that the hematological and biochemical parameters non-significantly $(p>0.05)$ differed between the crossbred groups. From the experiment, the higher amount of $\mathrm{Hb}(11 \mathrm{~g} / \mathrm{dL})$ and PCV $(40 \%)$ was found in $\mathrm{HF}$ and RCC cows, respectively. The TLC was higher in SS and RCC but the TEC was recorded stable along with a slight increment in RCC. As far as the biochemical parameters are concerned, the blood urea concentration was found higher (28 $\mathrm{mg} / \mathrm{dL}$ ) in $\mathrm{HF}$ and RCC lactating cows. The same pattern was observed in the case of albumin concentration. On the contrary, the lowest value of Calcium was found in RCC but the Phosphorus concentration showed a little higher in RCC. It can be concluded that the overall herd health was satisfactory based on the blood profile parameters.
\end{abstract}

Key words: blood profile, crossbreds, lactating cows, dairy farm

\begin{tabular}{|c|c|}
\hline imal Husbandry Association. All righ & Bang. J. Anim. Sci. 2019. 48 (2):139-144 \\
\hline $\begin{array}{l}\text { Lactating cows are the most important animal in } \\
\text { a dairy farm because the farm milk production } \\
\text { along with its income depends on those cows. } \\
\text { The herd health of the cows can be evaluated and } \\
\text { relies upon hematologic and biochemical profile of } \\
\text { blood for the maximum production (Coroian et } \\
\text { al., 2017). Blood parameters analysis is pre- } \\
\text { symptomatic diagnostic tool that can identify if } \\
\text { there are errors in nutrition or other } \\
\text { productive/reproductive disorder in lactating cows }\end{array}$ & $\begin{array}{l}\text { metabolically superior cows. Metabolic } \\
\text { disturbances, caused by inappropriate feeding } \\
\text { without manifestation of clinical symptoms are } \\
\text { significant in animal husbandry and may cause } \\
\text { insufficiently developed breeding cattle (Radostits } \\
\text { et al., 2003). For instances, the deficiency of } \\
\text { minerals, proteins and vitamins in the diet of } \\
\text { lactating cows not only causes profound changes } \\
\text { in metabolism (Parvu et al., 2011) but also reflect } \\
\text { the adaptability of cows to adverse environmental } \\
\text { conditions, as well as other stressors (Coroian et } \\
\text { al., 2017). }\end{array}$ \\
\hline
\end{tabular}
the influence of blood biochemical profile in cows with reproductive disorders and clinically healthy cows (Ruginosu et al., 2011), cows in lactation (Filipejová and Kovacik, 2009), the transition period in dairy cows (Seifi et al., 2007; QuirozRocha et al., 2009; Imhasly et al., 2014) and season influence on blood parameters in cows. The original intent of this blood profiling is to monitor metabolic health of the herd and identify

However, the hematological and biochemical profile within normal physiological limits reflects a good health status and is highly correlated with milk production (Axay et al., 2017). Environmental factors viz. ambient temperature, relative humidity and temperature-humidity index that affect hematological parameters in lactating cows (Mazzullo et al., 2014). Besides, the blood biochemical parameters influences both the lactation phase and level of production (Filipejová

*Corresponding author: msrsiddiki@bau.edu.bd 
and Kováčik, 2009; Joźwik et al., 2012). Furthermore, age of the lactating animals influence on hematology and biochemistry reference values for Holstein heifers (Lumsden et al., 1980). Similar studies repeatedly showed up with various factors to affect those blood parameters. Cozzi et al., 2011) has assessed the reference values for blood parameters in Holstein dairy cows can be influenced by the parity, lactation stage and season of production as a tool to predict the metabolic status of lactating cows. Nonetheless, variability of factors is responsible for individual and herd disparity in blood metabolite concentrations confusing elucidation (Van Saun, 2000).

Alike studies have been executed to another species. The hematological and biochemical parameters in normal cycling, pregnant and repeat-breeding buffaloes (Bubalus bubalis) maintained in isothermic and isonutritional conditions studied by Sabasthin et al. (2012). Metabolic profile in buffaloes has been also conducted for pre- and post-partum period (Coroian et al., 2017). Despite of many factors which have been estimated in correlation with the blood parameters in cows and/or heifers or other species, technological aspects such lactation length seems to present less interest, probably due to significant shortening of productive life in cows during the past decades. No report has been documented in the blood profile of lactating dairy cows kept in BAU Dairy Farm.

Thus, here we have estimated the hematological and biochemical changes that occur during lactations stage correlated with different crossbreds of lactating cows to assess the herd health status.

\section{Materials and Methods}

\section{Experimental animals}

The experiment was carried out at the Bangladesh Agricultural University (BAU) Dairy Farm, Department of Dairy Science, BAU, Mymensingh-2202, Bangladesh. Thirty-two (32) healthy lactating cows were selected from different crossbreds' viz. Jersey (J), Sindhi Sahiwal (SS), Holstein Friesian (HF), and Red Chittagong Cattle (RCC). Then, the cows were divided into four groups each with 8 (eight) animals. Within the group the homogenous pattern was achieved based on the farm records regarding the lactation stage, number of lactation, milk yield, and age of the animals. The average live weight of the grouped animals was $285 \pm 25 \mathrm{~kg}$. The animals were allowed to feed regular ration of the farm without any supplementation. Adlibitum water supply was ensured during the study. In addition, the animals were reared in a well-ventilated face-out stanchion barn and milked twice (morning and afternoon) a day.

\section{Blood collection and biochemical analysis}

Blood samples were collected from the jugular vein through cleaning with $70 \%$ ethyl alcohol, and then, a 45 degree single drive was performed with a syringe with needle. Afterward, blood was immediately drawn into a properly marked falcon tube and prevent to clot at room temperature for 40-50 minutes in an undisturbed condition. The blood was collected in triplicate within a period of one month with one-week interval. In the laboratory, the blood samples were centrifuged at $3000 \mathrm{rpm}$ for 10 minutes. The samples were kept in an ice boxuntil reached at the laboratory. Then the serum was separated and poured into Eppendorf tubes and stored at $(-) 20^{\circ} \mathrm{C}$ until analyzed. All the blood biochemical parameters were estimated by using an Automatic Chemistry Analyzer URIT-810 (URIT Medical Electronic Company Limited, China), Department of Animal Nutrition Lab, BAU.

\section{Statistical analysis}

The data obtained from the laboratory tests were analyzed in Microsoft Excell-2010 and $p$ value $(p<0.05)$ was considered for level of significance.

\section{Results and Discussion}

\section{Blood Hematological Profile}

All hematological components were found nonsignificant $(p>0.05)$ in four groups of crossbred cows. Although the highest hemoglobin concentration $(11 \mathrm{~g} / \mathrm{dL})$ was found in HF cows at a time there was a lower trend as compared to other groups of lactating crossbreds (Tambare, 2005). Likewise, Hagawane et al., (2009) noted that non-significant differences in hematocrit values in different breeds and stages of lactation. It has been reported that hemoglobin, hematocrit and RBC values of calves during the first three months of lactation all were within the reference range (Knowles et al., 2000; Egli and Blum, 1998). The mean value of TLC in SS was $10.19 \mathrm{X}$ $103 / \mu$ l which showed slightly higher compared to other groups. Analogous findings were reported by Logdberg et al., (1987) who reported the same value in squirrel monkeys. It must be considered that RBC parameter changes may be attributed to iron content or availability of diet and/or physiologic occurrence during the 
interpretation of TEC in different groups. The amount of serum iron can differentiate these conditions from each other. It was reported that TLC count at birth tended to be above the upper limit of adult reference range but will drop to count within reference range at other sampling times (Knowles et al., 2000). Our results are inconsistent with Egli and Blum (1998) which reported that TLC counts were within reference range. Several authors suggested that, because the TEC number remained stable, whereas hemoglobin concentration and PCV decreased, there was development toward microcytic and hypochromic anemia (Jain, 1986). In the present study, concerning a declining trend in PCV and hemoglobin concentration, may implicate a state of microcytic change probably due to iron deficiency in the diet during the lactation phase (Knowles et al., 2000).

\section{Blood Biochemical Profile}

\section{Serum glucose}

In the present study, non-significant $(p>0.05)$ differences were observed in serum glucose concentrations between the crossbred cows. Though the serum glucose level is comparatively higher in Red Chittagong Cattle (RCC) and Jersey and lower volume of serum glucose was estimated in Sindhi-Sahiwal (SS) and Holstein Frisian (HF) crossbred lactating cows (Table 1). Comparing these values with standard reference value of serum glucose concentration in dairy cows is in the range of 2.1 to $3.9 \mathrm{mmol} / \mathrm{L}$ (Cozzi et al., 2011). It is quite evident that glucose concentration was within the reference range (data not shown) in RCC, J, and HF. But a decreasing trend was estimated in SS crossbreds. It is well-known that low glucose levels resulted in ketosis, poor production, and infertility (Manston et al., 1977). More recently Van Knegsel et al., (2005) have reported that low plasmas glucose levels are associated with decreased reproductive performance. Also, the quality and quantity of feed are the determiners of blood glucose level, blood glucose level tends to fall when the cattle were on pasture but remain high on a grain diet (Kay et al., 1976).

\section{Serum urea}

The concentration of serum urea was found nonsignificantly $(p>0.05)$ elevated in RCC and HF crossbred lactating cows and comparatively lower in J and SS crossbreds. According to different authors, the serum urea level recorded in lactating cows varies widely and it is difficult to imagine the abnormal values (Lager et al., 2012; Sabasthin et al., 2012; Shakeri et al., 2013). Though we had found a referred ranges for urea from 20 to $30 \mathrm{mg} / \mathrm{dL}$ (Kaneko et al., 2008) for cattle and the value may also distinct from each other according to breed, age and season. This indicates that the animal's protein intakes were satisfactory and were in good metabolic condition. But, we may allow the farm animal to have slightly more protein-rich feed to maintain a sound health condition in terms of blood urea availability. For example, the legumes are rich in protein and poor in energy, which may increase the amount of nitrogen in the diet, and subsequently urea in the blood. Similar studies were conducted in buffaloes were compared to pregnant and/or regularly cycling ones with the lactating buffaloes and found a decreasing trend of protein level, the reason behind it could be due to the diet of the animals (Sabasthin et al., 2012).

\section{Serum albumin}

Serum albumin concentration was nonsignificantly $(p>0.05)$ higher in RCC and HF crossbreds and a lower value was estimated in Jersey and SS. Comparing the serum albumin level in lactating cows to the estimated data of several authors is within the range of 2.6 to 3.8 $\mathrm{mg} / \mathrm{dL}$ (Sabasthin et al., 2012; El-Emam et al., 2014). In the current investigation, we found a lower value of albumin in comparison to the reference range. This might be attributed to the lower levels of protein-rich feed supplied in the diet during the production phase.

Table 1: The hematological parameters of different crossbred cows during lactation

\begin{tabular}{lrrrr}
\hline Group & \multicolumn{1}{c}{$\mathrm{Hb}(\mathrm{g} / \mathrm{dL})$} & \multicolumn{1}{c}{$\mathrm{PCV}(\%)$} & \multicolumn{1}{c}{$\mathrm{TLC}\left(\mathrm{X} 10^{3} / \mu \mathrm{l}\right)$} & \multicolumn{1}{c}{$\mathrm{TEC}\left(\mathrm{X} 10^{6} / \mu \mathrm{l}\right)$} \\
\hline $\mathrm{J}$ & $9.28 \pm 0.32$ & $33.1 \pm 1.70$ & $9.16 \pm 0.66$ & $5.89 \pm 0.44$ \\
$\mathrm{SS}$ & $9.92 \pm 0.17$ & $35.6 \pm 3.34$ & $10.19 \pm 0.39$ & $5.47 \pm 0.43$ \\
$\mathrm{HF}$ & $10.88 \pm 0.68$ & $38.1 \pm 1.68$ & $9.71 \pm 0.51$ & $5.83 \pm 0.19$ \\
RCC & $10.46 \pm 0.60$ & $39.5 \pm 3.88$ & $10.02 \pm 0.89$ & $6.40 \pm 0.52$ \\
p-value & 0.10 & 0.97 & 0.15 & 0.25 \\
\hline
\end{tabular}

Mean \pm SD. SS $=$ Sindhi Sahiwal cross, $\mathrm{J}=$ Jersey, HF $=$ Holstein Friesian cross, RCC $=$ Red Chittagong Cattle. $\mathrm{Hb}=$ Hemoglobin, $\mathrm{PCV}=$ Packed cell volume, $\mathrm{TLC}=$ Total leukocyte count, $\mathrm{TEC}=$ Total erythrocyte count 
Rafsanjanny et al. (2019) Bang. J. Anim. Sci. 48 (2):139-144

Table 2: The blood biochemical parameters of crossbred cows during lactation

\begin{tabular}{lrrrrr}
\hline Parameters & Jersey & \multicolumn{1}{c}{ SS } & HF & RCC & p-value \\
\hline $\begin{array}{l}\text { Serum Glucose } \\
(\mathrm{mmol} / \mathrm{L})\end{array}$ & $2.65 \pm 0.48$ & $2.09 \pm 0.64$ & $2.11 \pm 0.39$ & $2.41 \pm 0.60$ & 0.32 \\
Urea $(\mathrm{mg} / \mathrm{dL})$ & $17.05 \pm 6.525$ & $22.811 \pm 8.47$ & $28.13 \pm 7.02$ & $27.417 \pm 9.07$ & 0.11 \\
Albumin $(\mathrm{g} / \mathrm{dL})$ & $1.74 \pm 0.37$ & $1.754 \pm 1.09$ & $2.13 \pm 0.71$ & $2.46 \pm 1.01$ & 0.43 \\
Calcium $(\mathrm{mg} / \mathrm{dL})$ & $9.25 \pm 6.36$ & $8.51 \pm 4.35$ & $9.39 \pm 2.97$ & $6.36 \pm 1.76$ & 0.41 \\
Phosphorus $(\mathrm{mg} / \mathrm{dL})$ & $4.99 \pm 0.72$ & $5.298 \pm 1.94$ & $4.56 \pm 2.07$ & $5.89 \pm 2.36$ & 0.59 \\
\hline
\end{tabular}

Mean \pm SD. SS $=$ Sindhi Sahiwal cross, HF $=$ Holstein Friesian cross, RCC $=$ Red Chittagong Cattle.

It is evident from different literature that the decreasing trend in serum albumin has been reported as characteristics of liver disease, kidney disease, inflammatory conditions and malnutrition (Lager et al., 2012; Shakeri et al., 2013). The relationship between albumin and disease has been reported in the different trials that those calves which later developed scour fever has miserably lower serum albumin from birth (Cabello et al., 1977). A lower serum albumin association with diarrhea and felt that this was a dietary fault along with higher protein intake has been reported to increase serum albumin by Shetaewi et al., (1991). Thus, in the current investigation, in response to serum albumin, it can be recommended that the lower albumin level does not correspond the lower protein in diet rather the internal malfunction could be attributed.

\section{Serum calcium}

It was noted that non-significantly $(p>0.05)$ higher serum calcium was estimated in $\mathrm{HF}$ crossbred and the lower amount was estimated in RCC. The estimated value of $\mathrm{J}, \mathrm{SS}$ and $\mathrm{HF}$ crossbreds are supported by several authors (Mamun et al., 2013, Amle et al., 2014; Kumar, 2014). But the RCC breeds showed a calcium level below than the standard value which indicated this group of the cow were in calcium deficiency condition and they might be prone to milk fever as most significant was the association between cows with pre- or postpartum calcium concentrations below $8 \mathrm{mg} / \mathrm{dL}$. Either pre- or postpartum cows with serum total calcium $<8.0$ $\mathrm{mg} / \mathrm{dL}$ were 4 times more likely to have postpartum disease problems (Harris et al., 1990). According to mineral status, all the cows are safe from any mineral deficiency diseases except RCC crossbred cow. But no evidence of abnormalities attributed to calcium insufficiency was observed. There is some evidence that high calcium intake does not completely counteract the adverse effect of a high phosphorus intake, particularly from the diet. Many studies have shown that an increased phosphorus intake may have negative effects on the skeleton, whereas Calcium intake may have a protective effect on it.

\section{Serum phosphorus}

The serum phosphorus was also non-significantly ( $p>0.05$ ) different between the crossbred groups. Though we estimated a high level of phosphorus concentration in RCC and a lower level of calcium concentration was estimated in Jersey breeds. The result revealed that the phosphorus level of the crossbreds was estimated within the reference value. When phosphorus intake is low then decreased feed intake, fertility rate, ovarian activity, irregular estrous cycles, increased occurrence of cystic ovaries, delayed sexual maturity and low conception rates. Disturbances in ovulation along with the pituitary-ovarian axis could be caused by the marginal deficiency of phosphorus (Bhaskaran and Patil, 1982).Studies have shown that an increased Phosphorus intake may have negative effects on the skeleton, whereas higher Calcium intake may protect against the adverse skeletal effects of excess Phosphorus.Therefore, maintaining appropriate dietary Calcium to Phosphorus ratio is a key to preserving skeletal health especially during the early stage of lactation.

\section{Conclusion}

In the current study, the blood hematological and biochemical parameters of crossbred lactating cows in BAU dairy farm has been examined. The results demonstrate that the hematological and biochemical parameters non-significantly ( $p>0.05$ ) differed between the crossbred groups. Thus, the crossbred group of animals has more or less the same metabolic strength so far the blood profiles are concerned as a herd health indicator. 
It could be hypothesized that maintaining these biochemical parameters within the reference range may be an effective strategy for the treatment of the metabolic disorders, malnutrition along with supplying a balanced ration in the herd of lactating cows, however, there are still prerequisites to be tested in future studies.

\section{Acknowledgement}

Authors are thankful to Bangladesh Agricultural University Dairy Farm, Department of Dairy Science and Department of Animal Nutrition, Bangladesh Agricultural University, Mymensingh for providing necessary facility for conducting the experiment.

\section{Conflict of interest}

The authors have no conflict of interest to declare.

\section{References}

Amle M, V Patodkar, R Shelar and H Birade (2014). Serum biochemical levels of repeat breeder crossbred cows under rural condition of Satara District of Maharashtra. International Journal of Advanced Veterinary Science and Technology 3:109-113.

Axay J, N Haque, A Lateef, A Patel, P Patel and N Bhalakiya (2017). Study on blood metabolites and leukocyte indices of kutchi camels during different stages of lactation. Journal of Animal Health and Production 5(3):92-96.

Bhaskaran R and RV Patil (1982). Role of blood serum inorganic phosphorus on the oestrus cycle of cross-bred dairy heifers. Indian Veterinary Journal 59:518-520.

Cabello G, MC Michel, C Foucher and C Lafarge (1977). Composition of blood plasma (calcium, phosphorus, magnesium, proteins) during the neonatal period in the calf. Influence of the state of health. Annales de Recherches Vétérinaires (INRA Editions) 8 (3):203-211

Coroian CO, V Miresan, A Coroian, C Raducu, L Andronie, Z Marchis, S Terhes and MV Muntean (2017). Biochemical and haematological blood parameters at different stages of lactation in cows. Bulletin of University of Agricultural Sciences and Veterinary Medicine Cluj-Napoca. Animal Science and Biotechnologies 74(1):3136.

Cozzi G, L Ravarotto, F Gottardo, AL Stefani, B Contiero, L Moro, M Brscic, and $\mathrm{P}$ Dalvit (2011). Reference values for blood parameters in Holstein dairy cows: Effects of parity, stage of lactation, and season of production. Journal of Dairy Science 94(8):3895-3901.

Egli CP and JW Blum (1998). Clinical, haematological, metabolic and endocrine traits during the first three months of life of suckling Simentaler calves held in a cow-calf operation. Journal of Veterinary Medicine 45:99-118.

El shazly K (1952). Degradation of protein in the rumen of sheep 2 . The action of rumen microorganisms on amino acids. Biochemical journal 51(5):647-653

El-Emam GI, YH Hafez, HR Behery, EI Khalifa, EI Shehata, and ME Ahmed (2014). Growth performance, some rumen and blood parameters of growing rahmani lambs fed rations containing triticale or berseem silages and their mixture. Egyptian Journal of Sheep and Goat Sciences 9(1):67-76.

Filipejová T and J Kováčik (2009). Evaluation of selected biochemical parameters in blood plasma, urine and milk of dairy cows during the lactation period. Slovak Journal of Animal Science 42(Supplement 1):8-12.

Hagawane SD, SB Shinde, and DN Rajguru (2009). Haematological and blood biochemical profile in lactating buffaloes in and around Parbhani city. Veterinary World 2(12):467-469.

Harris Jr. B, D. Morse, HH Head, and HH Van Horn (1990). Phosphorus nutrition and excretion by dairy animals. Florida Cooperative Extension Service Circular-849. Florida Cooperative Extension Service, Gainesville, USA

Imhasly S, H Naegeli, S Baumann, $M$ von Bergen, A Luch, H Jungnickel and C Gerspach (2014). Metabolomic biomarkers correlating with hepatic lipidosis in dairy cows. BMC Veterinary Research 10(1):122.

Jain, NC (1986). Schalm's Veterinary Hematology $\left(6^{\text {th }}\right.$ edition), Fourth ed. Lea and Febiger, Philadelphia, USA

Joźwik A, N Strzałkowska, E Bagnicka, W Grzybek, J Krzyżewski, E Poławska, A Kołataj, JO Horbańczuk, (2012). Relationship between milk yield, stage of lactation, and some blood serum metabolic parameters of dairy cows. Czech Journal of Animal Science 57: 353-360.

Kaneko JJ, JW Harvey and ML Bruss (Eds.). (2008). Clinical biochemistry of domestic animals. Academic press. California, USA

Kay RM, W Little, and BA Kitchenham (1976). A comparison of the growth performance and blood composition of twin and singleton calves. Animal Science 22(1):19-25. 
Knowles TG, JE Edwards, KJ Bazeley, SN Brown, A Butterworth, and PD Warriss (2000). Changes in the blood biochemical and haematological profile of neonatal calves with age. Veterinary Record 147 (21):593-598.

Kumar AS (2014). Blood biochemical profile in repeat breeding crossbred dairy cows. International Journal of Veterinary Science 3(4):172-173.

Lager $\mathrm{K}$ and $\mathrm{E}$ Jordan (2012). The metabolic profile for the modern transition dairy cow. In Proceedings of the mid-south ruminant nutrition conference, Grapevine, TX, USA, (Ed. E Jordan) pp. 9-16. (Texas A and M University: College Station, TX)

Lögdberg B, M Berlin and A Schütz (1987). Effects of lead exposure on pregnancy outcome and the fetal brain of squirrel monkeys. Scandinavian Journal of Work, Environment and Health 13 (2):135-145.

Lumsden JH, K Mullen and R Rowe (1980). Hematology and Biochemistry Reference Values for Female Holstein Cattle. Canadian Journal of Comparative Medicine 44(1):24-31.

Mamun MA, MM Hassan, AH Shaikat, SKMA Islam, MA Hoque, M Uddin and MB Hossain (2013). Biochemical analysis of blood of native cattle in the hilly area of Bangladesh. Bangladesh Journal of Veterinary Medicine 11(1):51-56.

Manston R, BA Kitchenham and AF Baldry (1977). The influence of system of husbandry upon the blood composition of bulls and steers reared for beef production. British Veterinary Journal 133(1):37-45.

Mazzullo G, C Rifici, F Cammarata, G Caccamo, M Rizzo and G Piccione (2014). Effect of different environmental conditions on some haematological parameters in cow. Annals of Animal Science 14(4):947-954.

Parvu AE, C Craciun, S Tripon, SF Alb, MA Taulescu, $S$ Clichici and A Craciun (2011). Histopathological and ultrastructural investigation of gingival tissue from patients with chronic periodontitis. Age 16(1):186-193.

Quiroz-Rocha GF, SJ LeBlanc, TF Duffield, D Wood, KE Leslie and RM Jacobs (2009). Reference limits for biochemical and hematological analytes of dairy cows one week before and one week after parturition. The Canadian Veterinary Journal 50(4):383-388
Radostits OM (2003). Engineering veterinary education: a clarion call for reform in veterinary education-let's do it. Journal of Veterinary Medical Education 30(2):176-190.

Ruginosu E, S Creangă, M Sofronie, R Mălăncuş, V Boghian and G Solcan (2011). The biochemical profile in cows with reproductive disorders. Cercetari Agronomice in Moldova 44(2): 75-86.

Sabasthin A, VG Kumar, S Nandi and VC Murthy (2012). Blood haematological and biochemical parameters in normal cycling, pregnant and repeat breeding buffaloes (Bubalus bubalis) maintained in isothermic and isonutritional conditions. Asian Pacific Journal of Reproduction 1(2):117-119.

Seifi HA, M Gorji-Dooz, M Mohri, B Dalir-Naghadeh, and N Farzaneh (2007). Variations of energyrelated biochemical metabolites during transition period in dairy cows. Comparative Clinical Pathology 16(4):253-258.

Shakeri, P, A Riasi, M Alikhani, H Fazaeli and Ghorbani, GR (2013). Effects of feeding pistachio by-products silage on growth performance, serum metabolites and urine characteristics in Holstein male calves. Journal of Animal Physiology and Animal Nutrition 97(6): 1022-1029.

Shetaewi MM and $\Pi$ Ross (1991). Effects of concentrate supplementation and lasalocid on serum chemistry and hormone profiles in Rambouillet ewes. Small Ruminant Research 4(4):365-377.

Tambare PK (2005). Studies on Hypogalactia with Particular Reference to Metabolic Profile in Buffaloes, Dissertation of Masters' of Veterinary Science in Veterinary Medicine, Maharashtra Animal and Fisheries Sciences university (MAFSU), Nagpur, India.

van Knegsel AT, $H$ Van den Brand, J Dijkstra, S Tamminga and B Kemp (2005). Effect of dietary energy source on energy balance, production, metabolic disorders and reproduction in lactating dairy cattle. Reproduction Nutrition Development 45(6): 665-688.

Van Saun RJ (2010). Blood profiles as indicators of nutritional status. Proceedings of 18th Annual Western Canadian Dairy Seminar, Red Deer, Alberta, Canada, 1-6 (2000) 